\title{
HUBUNGAN KEKUATAN DAYA LEDAK OTOT TUNGKAI DAN KOORDINASI MATA DAN TANGAN TERHADAP KETERAMPILAN JUMPSHOOT PADA PEMAIN PUTRA CLUB TUNAS (KELOMPOK UMUR 16 TAHUN) KOTA BENGKULU
}

\author{
Yarmani \\ Universitas Bengkulu \\ e-mail : Yarmani@unib.ac.id \\ Yoga Saputra \\ Universitas Bengkulu \\ Sofino \\ Universitas Bengkulu
}

\begin{abstract}
Abstrak
Penelitian ini bertujuan untuk mengetahui seberapa besar hubungan daya ledak otot tungkai dan koordinasi mata dan tangan terhadap keterampilan jumpshoot pada pemain putra club tunas (kelompok umur 16 tahun) Kota Bengkulu. Dalam penelitian ini menggunakan, metode korelasional. Tes yang di gunakan adalah tes daya ledak otot tungkai dan koordinasi mata dan tangan. Populasi dalam penelitian ini berjumlah 30 orang, sedangkan sampel yang di tetapkan dengan teknik total sampling yaitu seluruh populasi 30 orang. Sedangkan analisi data yang di gunakan teknik analisis korelasi sederhana dan korelasi ganda dengan taraf signifikan $\alpha=0,05$. Hasil analisis data menunjukkan bahwa 1) terdapat hubungan yang berarti antara daya ledak otot tungkai terhadap keterampilan jumpshoot sebesar 0,863 (sangat tinggi) dengan perolehan $r_{\text {hitung }} 0,863>r_{\text {tab }} 0,367$. 2) terdapat hubungan yang berarti antara koordinasi mata dan tangan terhadap keterampilan jumpshoot sebesar 0,392 (Rendah) dengan perolehan $r_{\text {hitung }} 0,397>r_{\text {tab }} 0,367$. 3) terdapat hubungan yang berarti antara daya ledak otot tungkai dan koordinasi mata dan tangan terhadap keterampilan jumpshoot sebesar 0,813 (Sangat besar) dengan perolehan $r_{\text {hitung }} 0,813>r_{\text {tab }} 0.367$.
\end{abstract}

Kata kunci : Daya Ledak Otot Tungkai, Koordinasi Mata Dan Tangan, Jumpshoot

\begin{abstract}
This study aims to determine how big is the relationship between leg muscle explosive power and eye and hand coordination to jumpshoot skills in the budding club male players (age group 16 years) Bengkulu City. In this study using the correlational method. The test used was a test of leg muscle explosiveness and eye and hand coordination. The population in this study amounted to 30 people, while the sample set with total sampling technique is the entire population of 30 people. While the data analysis used simple correlation analysis techniques and multiple correlations with a significant level $\alpha=0.05$. The results of data analysis showed that 1 ) there was a significant relationship between leg muscle explosive power and jumpshoot skills of 0.863 (very high) and the acquisition of r_calculate 0.863> r_tab0.3367. 2) there is a significant relationship between eye and hand coordination on jumpshoot skills of 0.392 (Low) with the acquisition of $r_{-}$calculate 0.397> r_tab0.376. 3) there is a significant relationship between leg muscle explosive power and eye and hand coordination to jumpshoot skills of 0.813 (very large) and the acquisition of $r_{-}$count $0.813>$ r_tab0.367.
\end{abstract}

Keywords: Leg Muscle Explosion Power, Eye and Hand Coordination, Jumpshoot 


\section{PENDAHULUAN}

Sasaran pencapain proses pendidikan memalui penjasorkes di arahkan menitik beratkan dan mengoptimalkan pembelajaran olah raga dalam bentuk permainan beregu yaitu salah satunya permainan bola basket, di samping permainan bola voly dan bola kaki terpilinnya permainan bola basket sebagai alat pencapain sasaran dan tujuan - tujuan pendidikan karena dengan pembelajaran permainan bola basket akan mampu memfalisitasi terbentuknya pengetahuan (kognitif), dan lain - lain, bahkan kepribadian dan emosional siswa dengan baik. Olahraga pendidikan dilaksanakan baik pada jalur pendidikan formal mauppun non formal melalui kegiatan intra kurikuler dan / ekstrakulikuler ( pengembangan diri ) ( UU RI NO. 3 Tahun 2005 tentang sistem keolahragaan Nasiona. Pasal 18 : ayat 2 ). Pengembangan diri adalah suatu kegiatan pengembangan diri jalan pembinaan kesiswaan disamping jalan pembinaan osis, latihan kepemimpinan, dan Wawasan Widyata Mandala (Depdikbud RI, 1994 : 3)

Permainan bola basket sendiri pada dasarnya merupakan salah satu latihan tentang kekompakan dalam tim dan mempelajari teknik dasar bola basket yang di ciptakan dan di susun secara beraturan dalam rangka membina pertumbuhan dan pembentukan tubuh, kekompakan serta perkembangan pribadi secara harmonis. Menurut (Adnan Fardi, 2000:3) Permainan bola basket itu adalah permainan sederhana yang di mainkan oleh 5 orang dalam satu tim dan melibatkan banyak orang untuk bergerak secara fisik. Permainan bola basket sangat digemari oleh kaum remaja hampir di seluruh pelosok dunia dan banyak menyita perhatian masyarakat pada umumnya. Sedangkan menurut (Jon Oliver, 2007:6) bahwa pengertian bola basket adalah Salah satu olahraga paling populer di dunia, penggemarnya yang berasal dari segala usia merasakan bahwa bola basket adalah olahraga yang paling menyenangkan, kompetitif, mendidik, menghibur, dan menyehatkan.

Bola basket merupakan permainan yang gerakannya kompleks yaitu gabungan dari jalan, lari, lompat, dan unsur kekuatan, kecepatan, reaksi, ketepatan, kelenturan, daya tahan, keseimbangan, daya ledak, kelincahan dan koordinasi gerak. Bolabasket merupakan olahraga yang mengandung unsur-unsur gerakan yang komplit dan beragam artinya gerakan-gerakan yang dibutuhkan dalam bermain bolabasket merupakan gabungan dari unsur gerakan yang saling menunjang.

Adapun teknik-teknik dasar yang harus dimiliki oleh para pemain adalah melempar (passing) dan menangkap (catcing), menggiring (dribbling), dan menembak (shooting) (Fardi,1999:24). Variasi dari teknik dasar melempar (passing) adalah (1) passing/operan dengan dua tangan : the two hand chest pass (operan setinggi dada/tolakan dada), the over head pass (operan ayunan bawah), (2) passing/operan dengan satu tangan : the side armpass/the base ball pass (operan samping), the lop pass (operan lambung), the back pass (operan belakang), the jump hanh pass (operan lompat).

Kurang berkembangnya prestasi pemain ini mungkin salah satu penyebabnya adalah karena sering mengabaikan unsur unsur dasar yang dapat mendukung kemampuan pemain seperti kondisi fisik yaitu diantaranya daya ledak otot tungkai yang sangat berperan dalam melakukan teknik jumpshoot itu sendiri. Terutama pada kekuatan dan kecepatan untuk menghasilkan daya ledak. Dari sekian banyak teknik bola basket, jumpshoot merupakan teknik dasar yang harus dimiliki oleh seorang pemain basket yang melakukan serangan dan menciptakan poin dalam sebuah pertandingan. masalah yang timbul pada club bola basket Tunas (kelompok umu r 16 tahun) Kota Bengkulu yaitu : kurang bisa pemain mengaplikasikan gerakan jumpshoot yang baik dan benar, kurang besarnya daya ledak otot tungkai, berat badan mempengaruhi tinggi, lompatan, koordinasi mata, kurang kuatnya otot lengan, dan tangan kurang maksimal saat melakukan tembakan, kekuatan pergelangan tangan, dan penguasan teknik Jumpsoot kurang baik.

Berdarkan peristiwa diatas penulis tertarik untuk melakukan penelitian tenang hubungan Exsplosive Power daya ledak otot tungkai dan koordinasi mata - tangan terhadap 
gerakan Jumpshoot, dengan judul "Hubungan kekuatan daya ledak otot tungkai dan koordinasi mata - tangan terhadap gerakan jumpshoot pada pemain putra klub bola basket Tunas (kelompok umur 16tahun)kota Bengkulu".

\section{METODE}

Jenis penelitian ini adalah termasuk jenis penelitian korelasional. Hal ini sesuai dengan pendapat (Ruseffendi, 1994:31 dalam skripsi Reindo Febrinaldo 2013:23) bahwa penelitian korelasional adalah "Suatu penelitian yang dirancang untuk menentukan tingkat hubungan variabel-variabel dalam suatu populasi yang bertujuan untuk mengetahui berapa besar kontribusi variabel bebas terhadap variabel terikat, Populasi penelitian ini adalah wilayah generalisasi yang terdiri atas: objek\subjek yang mempunyai kualitas dan karakteristik tertentu yang di tetapkan oleh peneliti (Sugiono 2010: 117) yaitu hanya laki - laki saja, populasi adalah keseluruhan subjek penelitian. Populasi dalam penelitian ini adalah seluruh pemain yang latihan di club Tunas (kelompok umur 16 tahun) berjumlah 30 . agar lebih jelasnya dapat dilihat pada tabel berikut.

Yang menjadi sampel dalam penelitian ini adalah selruh pemain putra club Tunas (kelompok umur 16 tahun) yang berjumlah 30 orang. Adapun teknik pengambilan sampel dalam penelitian ini adalah total sampling. (Arikunto 2006:131). Mengingat jumlah populasinya lebih sedikit dari 100 orang. Karena apabila jumlah populasinya yang sedikit dari 100 orang, maka sebaiknya semua populasi dijadikan sampel. Karena populasi hanya berjumlah 30 orang, jadi semuanya dijadikan sampel. Penggunaan ini berlaku jika anggota populasi relatif kecil. Jenis data yang digunakan dalam penelitian ini adalah data primer yang diambil langsung dari tes dan pengukuran terhadap atlet yang terpilih menjadi sampel data yang meliputi a) tes vertical jump b) tes koordinasi mata - tangan c) tes keterampilan jumpshoot basket. Sedangkan data sekundernya berupa data dokumentasi dari pelatih dan pengurus tim bolabasket club Tunas (kelompok umur 16 tahun).
Tabel 1. Norma Interprestasi koefisien korelasi

\begin{tabular}{l|l}
\hline $0,80-1,000$ & Sangat Tinggi \\
\hline $0,60-0,799$ & Tinggi \\
\hline $0,40-0,599$ & Cukup \\
\hline $0,20-0,399$ & Rendah \\
\hline $0,00-0,199$ & Sangat rendah \\
\hline
\end{tabular}

\section{Teknik analisis data}

Untuk mengetahui seberapa besar hubungan daya ledak otot tungkai dan koordinasi maa dan tangan terhadap kemampuan jumpshoot, maka data yang di peroleh dianalisi dengan menggunakan rumus statistik berupa uji normalitas dan korelasi :

\section{HASIL DAN PEMBAHASAN}

1. Terdapat Kontribusi Yang Berarti Antara Daya Ledak Otot Tungkai Terhadap keterampilan jumpshoot pada pemain putra club tunas (Kelompok Umur 16 hanun) Kota Bengkulu

Seorang Pemain basket putra haruslah mempunyai daya ledak otot tungkai yang baik untuk menampilkan lompatan yang tinggi. Daya ledak otot tungkai sangat berperan penting dalam melompat, sehingga terlihat keefektifan dan efisiensi gerakan yang mendukung kemampuan pemain untuk melakukan tembakan jumpshoot.

Apabila daya ledak otot tungkai yang dimiliki belum maksimal akan dapat mempengaruhi lompatan. Apabila hal ini dibiarkan terus menerus, maka ide olahraga Bola Basket tidak akan tercapai dan prestasi tidak akan dapat diperoleh. Sebaliknya, apabila daya ledak otot tungkai yang dimiliki pemain baik sekali, gerakan akan dapat tercipta dan ide olahraga silat akan terjadi serta pemain dan club tersebut dapat berprestasi.

Pada tahap pengujian normalitas data hasil pengujian untuk daya ledak otot tungkai $\left(X_{1}\right)$, di dapatkan skor $L_{0}=0,054$ dengan $n=30$, sedangkan $L_{\text {tab }}=$ pada taraf pengujian signifikansi $\alpha=0,05$ di peroleh 0,161 yang lebih besar dari Lo sehingga dapat di simpulkan bahwa skor yang di peroleh dari daya ledak otot tungkai berdistribusi normal. 
Hasil penelitian membuktikan bahwa perolehan $r$ hitung sebesar 0,803 dan $r$ tab dalam taraf $\alpha=0,05$ sebesar 0,367 dengan demikian $r$ hitung $0,83>r$ tab 0,367 , Besarnya hubungan daya ledak otot tungkai terhadap keterampilan jumpshoot yaitu sebesar 0,863 (Sangat Tinggi). Artinya terdapat hubungan yang berarti antara daya ledak otot tungkai dengan keterampilan jumpshoot pada pemain putra club Tunas (kelompok umur 16 tahun) Kota Bengkulu.

2. Terdapat hubungan Yang Berarti Antara koordinasi mata dan tangan terhadap keterampilan jumpshoot pada pemain putra club Tunas (kelompok Umur 16 Tahun) Kota Bengkulu

Koordinasi adalah kemampuan seseorang untuk serangkaian beberapa unsur gerak menjadi satu gerakan yang selaras sesuai dengan tujuannya (Suharno H.P., 1981: 29). Koordinasi diperlukan untuk menyatukan dari beberapa unsur sehingga dapat membuat satu tujuan yang sama. Disini penulis memerlukan dua unsur yaitu koordinasi mata tangan dalam melakukan gerakan jumpshoot. Selain peran dari koordinasi, power otot tungkai juga menjadi unsur pendukung dalam menunjang keterampilan jumpshoot. Apabila koordinasi mata dan tangan yang dimiliki belum maksimal akan dapat mempengaruhi lompatan dan saat melakukan tembakan. Apabila hal ini dibiarkan terus menerus, maka ide olahraga pemain tidak akan tercapai dan prestasi tidak akan dapat diperoleh. Sebaliknya, apabila koordinasi mata dan tangan sangat baik sekali, maka hasil akan dapat tercipta dan ide olahraga Basket akan terjadi serta pemain dapat berprestasi.

Pada tahap pengujian normalitas data hasil pengujian untuk koordinasi mata dan tanagn $\left(\mathrm{X}_{2}\right)$, di dapatkan skor $\mathrm{L}_{\mathrm{o}}=0,038$ dengan $n=30$, sedangkan $L_{\text {tab }}=$ pada taraf pengujian signifikansi $\alpha=0,05$ di peroleh 0,161 yang lebih besar dari Lo sehingga dapat di simpulkan bahwa skor yang di peroleh dari daya ledak otot tungkai berdistribusi normal.
Hasil penelitian membuktikan bahwa perolehan $r$ hitung sebesar 0,392 dan $r$ tab dalam taraf $\alpha=0,05$ sebesar 0,367 dengan demikian $r$ hitung $0,392>r$ tab 0,367 , Besarnya kontribusi daya ledak otot tungkai terhadap keterampilan jumpshoot yaitu sebesar 0,392 (Rendah). Artinya terdapat hubungan yang berarti antara koordinasi mata dan tangan terhadap keterampilan jumpshoot pada pemain putra club tunas (kelompok umur 16 tahun) kota bengkulu.

3. Terdapat hubungan yang berarti antara daya ledak otot tungkai dan koordinasi mata dan tangan terhadap keterampilan jumpshoot pada pemain putra club Tunas (kelompok Umur 16 Tahun) Kota Bengkulu.

Tembakan jumpshoot merupakan salah satu teknik dasar yang sangat penting dimiliki oleh pemain Basket untuk menciptakan point yang lebih baik. Daya ledak otot tungkai berhubungan dengan penggunaan tenaga otot-otot tungkai secara keseluruhan pada pergerakan keterampilan jumpshoot yang ingin dilakukan secara akurat dan cepat dalam waktu yang singkat terhadap lawan. Selanjutnya, koordinasi mata dan tangan berhubungan dengan tembakan jumpshoot agar dapat leluasa melihat Ring pada saat melakukan tembakan jumpshoot. Dari daya ledak otot tungkai dan koordinasi mata dan tangan memberikan hubungan yang berarti terhadap keterampilan jumpshoot pada pemain putra club tunas (kelompok umur 16 tahun) kota bengkulu.

Pada tahap pengujian normalitas data keterampilan jumpshoot club Tunas (Y), skor $L_{0}=0,051$ dengan $n=30$, sedangkan $L_{\text {tab }}$ pada taraf pengujian signifinakan $\alpha$ $=0,05$ di peroleh 0,161 yang lebih besar dari Lo sehingga dapat di simpulkan bahwa skor yang di peroleh dari keterampilan para pemain putra club tunas (kelompok umur 16 tahun) Kota Bengkulu berdistribusi normal.

Hasil penelitian membuktikan bahwa terdapat hubungan yang berarti antara kemampuan daya ledak otot tungkai dan koordinasi mata dan tanagn secara bersama-sama terhadap keterampilan jumpshoot pada pemain putra club Tunas 
(Kelompok Umur 16 Tahun) Kota Bengkulu. Hasil ini ditandai dengan perolehan $\mathrm{R}$ hitung sebesar 0,813 dan $r_{\text {tabel }}$ dalam taraf $\alpha=0,05$ sebesar $=0,367$ dengan demikian $r$ hitung $0,813>r$ table 0,367 , Besarnya hubungan antara daya ledak otot tungkai dan koordinasi mata dan tangan terhadap keterampilan jumpshoot pemain putra club Tunas yaitu sebesar 0,813 (sangat tinggi). artinya daya ledak otot tungkai dan koordinasi mata dan tangan yang dimiliki atlet secara bersama-sama memiliki hubungan yang signifikan terhadap keterampilan jumpshoot pada pemain basket putra club Tunas (Kelompok Umur 16 Tahun) Kota Bengkulu.

\section{PENUTUP}

\section{SIMPULAN DAN SARAN}

Berdasarkan hasil penelitian yang telah diuraikan pada bab terdahulu dapat dikemukakan kesimpulan sebagai berikut:

1. Terdapat hubungan yang signifikan antara vertical jump terhadap keterampilan jumpshoot pada atlet bola basket club Tunas dari 30 pemaian dengan hasil 0,863 (Sangat Tinggi).

2. Terdapat hubungan yang signifikan antara koordinasi mata dan tangan terhadap keterampilan jumpshoot terhadap atlet bola baske club Tunast dari 30 pemain dengan hasil 0,392 (Rendah)

3. Terdapat hubungan yang signifikan antara daya ledak otot tungkai dan koordinasi mata dan tangan terhadap keterampilan jumpshoot atlet bola basket club Tunas yaitu 0,813 .

Berdasarkan pada simpulan di atas maka penulis dapat memberikan saran-saran yang dapat membantu mengatasi masalah yang ditemui dalam pelaksanaan keterampilan jumshoot dalam olahraga bola basket yaitu :

1. Berdasarkan pada hasil penelitian ini, maka disarankan kepada para pelatih serta para pembina olahraga bola basket, untuk memperhatikan unsur-unsur latihan vertical jump dan koordinasi mata dan tangan dalam meningkatkan keterampilan jumpshoot atlet bola basket .

2. Setiap pelaksanaan pengetesan yang mempergunakan alat tes perlu memperlihatkan prosedur pemakain alat tes agar tidak terjadi kesalahan dalam penggunaan.

3. Diharapkan kepada peneliti yang lain agar dapat melihan beberapa faktor lain yang belum diperhatikan dalam penelitian ini.

4. Dalam penelitian ini karena sampel penelitian masih terbatas maka disarankan kepada peneliti lain, yang ingin meneliti hal yang sama, agar memperbanyak sampelnya.

\section{DAFTAR PUSTAKA}

Adnan Fardi, 2000: Bola Basket dasae. Padang FIK-Universitas Padang

Ano, Anwar. 2010. Permainan Bola Basket. Fakultas keguruan dan IImu Pendidikan Universitas Haluoleo, Kendari.

Arikunto, suharsimi, 2011: dasar - dasar evaluasi pendidikan. Jakarta: Bumi Aksara.

Kanchan dan Adhikari Manju. 2011. Effect of PlyometricTraining On Armand Leg Strength betweenBasket Ball and Volley Ball Players. 12 Assistant Professor, Department of Physical Education, Swami Vivekanand Subharti University, Meerut, Uttar Pradesh, INDIA. VSRD Technical \& NonTechnical Journal Vol. 2 (9), 2011.

Oliver, Jon. 2007: Dasar - dasar bola basket. Bandung : pakar raya

Reindo febrinaldo, 2013: Hubungan daya ledak otot tungkai terhadap kemampuan jumpshoot pada siswa SMK Negeri 1 Arga Makmur Kabupaten Bengkulu Utara

Ruseffendi. 2001: Dasar - dasar penelitian pendidikan dan bidang noneksata lainnya Semarang : IKIP Semarang Press

Suharno HP. 1986. Ilmu coach umum. Yogyakarta: FKIP Universitas Negeri Yogyakarta. 